\title{
Isolation and characterizations of a novel recombinant scFv antibody against exotoxin A of Pseudomonas aeruginosa
}

\author{
Zahra Shadman ${ }^{1,2}$, Safar Farajnia ${ }^{1,3^{*}}$ (D), Mohammad Pazhang ${ }^{2}$, Mohammadreza Tohidkia ${ }^{4}$, Leila Rahbarnia ${ }^{5}$, \\ Saeed Najavand ${ }^{3}$ and Sayna Toraby ${ }^{3}$
}

\begin{abstract}
Background: Pseudomonas aeruginosa is the leading cause of nosocomial infections, especially in people with a compromised immune system. Targeting virulence factors by neutralizing antibodies is a novel paradigm for the treatment of antibiotic-resistant pseudomonas infections. In this respect, exotoxin A is one of the most potent virulence factors in P. aeruginosa. The present study was carried out to identify a novel human scFv antibody against the $P$. aeruginosa exotoxin A domain I (ExoA-DI) from a human scFv phage library.
\end{abstract}

Methods: The recombinant ExoA-DI of P. aeruginosa was expressed in E. coli, purified by Ni-NTA column, and used for screening of human antibody phage library. A novel screening procedure was conducted to prevent the elimination of rare specific clones. The phage clone with high reactivity was evaluated by ELISA and western blot.

Results: Based on the results of polyclonal phage ELISA, the fifth round of biopanning leads to the isolation of several EXoA-DI reactive clones. One positive clone with high affinity was selected by monoclonal phage ELISA and used for antibody expression. The purified scFv showed high reactivity with the recombinant domain I and fulllength native exotoxin $\mathrm{A}$.

Conclusions: The purified anti-exotoxin A scFv displayed high specificity against exotoxin A. The human scFv identified in this study could be the groundwork for developing a novel therapeutic agent to control P. aeruginosa infections.

Keywords: Phage display, Pseudomonas aeruginosa, Exotoxin A, Human single chain antibody

\section{Background}

Pseudomonas (p.) aeruginosa is the most common cause of nosocomial infections leading to a high mortality rate, especially in people with cystic fibrosis, neoplastic disease, and severe burns [1]. Currently, the outbreak of antibiotic resistant strains has become one of the serious challenges for global health. Toxins play an essential role in bacterial

\footnotetext{
* Correspondence: farajnia@gmail.com

'Drug Applied Research Center, Tabriz University of Medical Sciences, Tabriz, Iran

${ }^{3}$ Biotechnology Research Center, Tabriz University of Medical Sciences, Tabriz, Iran

Full list of author information is available at the end of the article
}

pathogenesis. $P$. aeruginosa produces several types of toxins, including exotoxin $\mathrm{A}$, phosphorylase $\mathrm{C}$, hemolysin, and exoenzyme $\mathrm{S}$ which among them, exotoxin A plays a major role in the progress and prognosis of $P$. aeruginosa infections. Exotoxin $\mathrm{A}$ is a single-chain polypeptide with a molecular weight of 66.583, consisting of 613 amino acids comprised of three domains [2,3]. Domain I is responsible for the attachment of toxin to the cell receptor and comprising two subdomain Ia (amino acids 1 to 252) and Ib (amino acids 365 to 404). The function of domain Ib is not well characterized, but it may be necessary for the secretion or activity of the toxin. The second domain comprises

(C) The Author(s). 2021 Open Access This article is licensed under a Creative Commons Attribution 4.0 International License, which permits use, sharing, adaptation, distribution and reproduction in any medium or format, as long as you give appropriate credit to the original author(s) and the source, provide a link to the Creative Commons licence, and indicate if changes were made. The images or other third party material in this article are included in the article's Creative Commons licence, unless indicated otherwise in a credit line to the material. If material is not included in the article's Creative Commons licence and your intended use is not permitted by statutory regulation or exceeds the permitted use, you will need to obtain permission directly from the copyright holder. To view a copy of this licence, visit http://creativecommons.org/licenses/by/4.0/. The Creative Commons Public Domain Dedication waiver (http://creativecommons.org/publicdomain/zero/1.0/) applies to the data made available in this article, unless otherwise stated in a credit line to the data. 
amino acids 253 to 364, consists of 6 alpha helix sequences, and is essential for transferring the toxin over the membrane. The third domain (405 to 613 amino acids) is the enzymatic and catalytic domain with ADP ribosyl transfer activity, which inhibits protein synthesis ultimately results in cell death [4]. In addition to the above mentioned domains, there are two crucial motifs inside exotoxin A. The first motif (280-274 RHRQPRG amino acids) is located in domain II, appears on the toxin's external surface, and is broken down by the eukaryotic proteases. The second motif (the REDLK-591913-609) is located at the toxin's carboxylic end and is responsible for retaining the toxin in the endoplasmic reticulum compartment. Both motifs are essential for toxicity [4]. It has shown that antibodies against Exotoxin A can significantly increase the survival rate of infected subjects [5]. Hence the development of anti-exotoxin A antibody is of great interest for the treatment of pseudomonas infections.

At present, human scFv phage libraries have provided a quick and reliable approach to develop human antibodies against almost any antigen. This study aimed to identify a human anti-exotoxin $\mathrm{A} s \mathrm{sFv}$ and evaluate its specificity to $P$. aeruginous exotoxin A.

\section{Methods}

\section{scFv-phage library, bacterial strains, and components}

The semisynthetic human $\mathrm{scFv}$ phage libraries I \& J (Tomlinson I J), E. coli strains (HB2151 and TG1), and KM13 helper phage were from the Medical Research Council (MRC), Cambridge. E. coli BL21(DE3) were from Novagene [6, 7].

\section{Expression and purification of exotoxin A domain I}

E. coli containing the ExoA-DI encoding construct were cultured in LB media and used for plasmid extraction by FAVORGEN plasmid extraction kit according to the manufacturer instruction. The expression construct was then transformed into E. coli BL21, cultured in LB media and induced with IPTG $(0.5 \mathrm{mM})$. For optimized expression, we examined different induction times, and $21 \mathrm{~h}$ was selected as the best induction time. The expression was assessed by SDS-PAGE. For purification, the bacteria were cultured in $200 \mathrm{ml}$ volume at $37^{\circ} \mathrm{C}$ and lysed by sonication. The inclusion body was washed by washing buffer, solubilized in $8 \mathrm{M}$ urea, and purified by $\mathrm{Ni}$ NTA column. After that, the recombinant ExoA-DI was refolded by stepwise removal of urea by dialysis [8].

\section{scFv phage library screening}

After the amplification of Tomlinson I library, it was screened for six rounds against ExoA-DI protein [9]. The biopanning process was started with $100 \mu \mathrm{g} / \mathrm{ml}$ ExoA-DI on a Maxisorb 96-well plate in PBS buffer [10]. During biopanning rounds, to prevent the elimination of specific rare clones, the concentration of domain I protein was kept constant [10-12].

To increase the screening stringency, the time of incubation of phage pool with antigen was decreased and washing numbers between screening rounds were increased (Table 1). In the beginning, the domain I - immobilized plate was blocked with 3\% Bovine Serum Albumin (BSA) for $2 \mathrm{~h}$, then $10^{12-13}$ pfu phages were added into the plates. After the incubation for $60 \mathrm{~min}$ at room temperature (RT), the plate was washed with PBS containing $0.1 \%$ Tween 20 (PBS-T), and trypsin-PBS $(100 \mu \mathrm{l}$ of $10 \mathrm{mg} / \mathrm{ml}$ trypsin stock solution in $10 \mathrm{ml}$ PBS) was used for elution of the bound phages (Table 1). The biopanning rounds were continued to reach the maximum OD in polyclonal phage ELISA. Totally, six rounds of biopanning were carried out to select domain I - specific phage clones. However, the biopanning was done until the sixth round; the results increased until the fifth round of enrichment. In the sixth round, the rate of enrichment was decreased, which indicated the completion of biopanning.

\section{Investigation of the specificity of the phage clones by polyclonal phage ELISA}

To investigate the specificity of selected phages from each round, a polyclonal phage ELISA against ExoA-DI was performed. For this purpose, $60 \mu \mathrm{g} / \mathrm{ml}$ ExoA-DI was coated into the ELISA plates and incubated at $4{ }^{\circ} \mathrm{C}$ overnight. After blocking with 3\% BSA for $1 \mathrm{~h}$, the eluted phages from each round (1:10 dilutions in 1\% BSA-PBS) were added to the plates and incubated for $1 \mathrm{~h} \mathrm{RT}$. After that, the plates were incubated with anti-M13- HRP (1: 2000 dilutions in 1\% BSA-PBS) for $1 \mathrm{~h}$. The reactivity was determined using TMB substrate. The optical density was recorded via ELISA Reader at $450 \mathrm{~nm}$.

\section{Selection of scFvs clones to ExoA-DI}

The single colonies were randomly selected from the fifth round of screening and used to identify specific $\mathrm{scFv}$ clones by monoclonal phage ELISA. For this

Table 1 Data related to antigen concentrations, blocking buffers, Tween 20 percentage and washing numbers during six biopanning rounds

\begin{tabular}{llllllll}
\hline Rounds & I & II & III & IV & V & VI & VII \\
\hline Protein $(\mu \mathrm{g} / \mathrm{ml})$ & 375 & 250 & 150 & 120 & 150 & 150 & 150 \\
Blocking buffers & $\% 2$ & $\% 3$ & $\% 2$ & $\% 3$ & $\% 2$ & $\% 3$ & $\% 2$ \\
& skim & BSA & skim & BSA & skim & BSA & skim \\
& milk & & milk & & milk & & milk \\
$\begin{array}{l}\text { \% Tween 20 } \\
\text { T0.1 }\end{array}$ & $\% 0.1$ & $\% 0.1$ & $\% 0.1$ & $\% 0.1$ & $\% 0.1$ & $\% 0.1$ \\
$\begin{array}{l}\text { Washing } \\
\text { numbers }\end{array}$ & 3 & 20 & 10 & 20 & 20 & 20 & 25 \\
$\begin{array}{l}\text { Phage } \\
\text { incubation time } \\
\text { (hrs) }\end{array}$ & 2 & 2 & 2 & 2 & 2 & 2 & 2 \\
\hline
\end{tabular}


purpose, the individual colonies were inoculated into 2 XTY medium $(1 \%[\mathrm{w} / \mathrm{v}]$ yeast extract, $1.6 \%[\mathrm{w} / \mathrm{v}]$ tryptone, and $0.5 \%[\mathrm{w} / \mathrm{v}]$ sodium chloride) containing $4 \%$ glucose and $100 \mu \mathrm{g} / \mathrm{ml}$ ampicillin in a 96 well plate. The plate was incubated at $37^{\circ} \mathrm{C}$ for $2 \mathrm{~h}[18,19]$. After adding $10^{9}$ helper phages to the wells and incubating for $1 \mathrm{~h}$ at $37^{\circ} \mathrm{C}$, the plate was centrifuged at $3000 \mathrm{xg}$ for $10 \mathrm{~min}$. The supernatants were aspirated off and the bacterial pellet was resuspended in 2xTY medium containing $50 \mu \mathrm{g} / \mathrm{ml} \mathrm{kanamycin} \mathrm{and} 100 \mu \mathrm{g} / \mathrm{ml}$ ampicillin. The cultures were continued overnight at $30^{\circ} \mathrm{C}$ in a shaking incubator $(250 \mathrm{rpm})$ and culture supernatants (1:2 dilution in $1 \%$ BSA-PBS) were utilized for phage ELISA as described above.

\section{Screening of clones via soluble fragment ELISA}

All positive clones were initially confirmed by PCR with LMB3 and PHEN specific primers shown in Table 2 [13]. An $\mathrm{scFv}$ ELISA was used to evaluate the specificity of positive phage clones against Exo A DI. For this, a positive phage clone with high OD in phage ELISA was cultured in 2 XTY medium containing ampicillin and $0.1 \%$ glucose at $37^{\circ} \mathrm{C}$. The expression of antibody was induced by 0.5 $\mathrm{mM}$ IPTG at OD600 $=0.9$, and the culture was continued at $200 \mathrm{rpm}$ overnight at $37^{\circ} \mathrm{C}$. The soluble scFvs were collected from the periplasmic fraction and used for ELISA. For this purpose, the ELISA plate was coated with ExoADI $\left(60 \mu \mathrm{g} / \mathrm{ml}\right.$ overnight at $\left.4{ }^{\circ} \mathrm{C}\right)$, and blocked with $3 \%$ BSA for $2 \mathrm{~h}$ and washed with PBS-T. Then soluble scFvs were added to the plate in different dilutions, incubated for $1 \mathrm{~h}$, and washed with PBS-T. The plate was incubated with HRP conjugated Protein L (1:2000 dilutions in PBS-\% BSA) for $1 \mathrm{~h}$. The reaction was finally developed by TMB substrate, and the OD values were measured with ELISA reader at $450 \mathrm{~nm}$.

\section{Expression of soluble anti exotoxin A scFv in E. coli}

To increase the expression of selected $\mathrm{scFv}$, the sequence coding for $\mathrm{scFv}$ fragment was amplified by PCR and subcloned into the $p E T 28 a$ expression vector. The construct was transformed into E. coli BL21 (DE3) pLysS strain and cultured in LB media containing kanamycin $(5 \mathrm{mcg} / \mathrm{ml})$. The antibody expression was induced by $0.5 \mathrm{mM}$ IPTG at OD600 $=0.7$, culture was continued overnight at $22^{\circ} \mathrm{C}$ in a shaking incubator, and the expression was assessed by SDS-PAGE. The supernatant containing secreted antibody fragments was purified by Ni-NTA column and confirmed

Table 2 The sequence of primers used for sequencing of scFv clones

\begin{tabular}{lll}
\hline Primer & & Sequence \\
\hline Phen & Reverse & 5'-CAG GAA ACA GCT ATG AC-3' \\
LMB3 & Forward & 5'-CTA TGC GGC CCC ATT CA-3' \\
\hline
\end{tabular}

by $12 \%$ SDS-PAGE. Then the reactivity of the purified $\mathrm{scFv}$ was checked by the ELISA technique.

\section{Assessment of the reactivity of recombinant scFv with exotoxin $A$}

The specificity of the purified scFv to ExoA-DI was evaluated by western blot. For this, $2.5 \mu \mathrm{g}$ of purified ExoADI and $1 \mu \mathrm{g}$ of native exotoxin A were electrophoresed through a $12 \%$ SDS-PAGE and transferred onto PVDF membrane (Invitrogen, USA). The membrane was blocked with $5 \%$ Skim Milk-PBS overnight at $4{ }^{\circ} \mathrm{C}$ and incubated with the purified $\mathrm{ScFv}$ followed by adding HRP conjugated Protein L (1-1000 dilutions) as the secondary antibody. The reaction was developed by using the DAB substrate.

\section{Production of $P$. aeruginosa native exotoxin A}

For the production of native exotoxin $A$, the trypticase soy broth culture medium was dialyzed against $0.01 \mathrm{M}$ Tris buffer, $\mathrm{PH} 8$ at $4{ }^{\circ} \mathrm{C}$ for $24 \mathrm{~h}$. Then, the dialysate was sterilized by autoclave and enriched by $1 \%$ glycerol and $1 \mathrm{M}$ monosodium glutamate. $P$. aeruginosa strain PAO1 was cultured in this media at $32^{\circ} \mathrm{C}$ for $22 \mathrm{~h}$. Finally, the culture supernatant was concentrated with ammonium sulfate [14-16].

\section{Evaluation of the reactivity of recombinant scFV antibody with native exotoxin $A$}

The purified exotoxin A was coated in an ELISA plate overnight. Then, different dilutions of recombinant $\mathrm{scFv}$ antibody were added into the wells, and the reaction was determined according to the ELISA method described earlier.

\section{Results}

Enrichment and specificity of anti-exotoxin A phages during biopanning rounds

The enrichment rate of specific phages against ExoA-DI was calculated during five rounds of biopanning. As expected, in the first round of screening, the yield of specific phages to ExoA-DI was very low while, from the 3rd round, the elimination of nonspecific phages led to the enrichment of specific phages to $0.72 * 10^{-4}$ that continued during rounds 4 and 5 (Table 3 ). Totally, the eluted

Table 3 The input, output and input/output ratio of scFv phage clones during different rounds of biopanning

\begin{tabular}{llll}
\hline Round & Input (pfu) & Output (pfu) & Enrichment (output/input) \\
\hline $\mathbf{1}$ & $3.52^{*} 10^{12}$ & $1.40^{*} 10^{6}$ & $0.39^{*} 10^{-6}$ \\
$\mathbf{2}$ & $1.40^{*} 10^{12}$ & $1.94^{*} 10^{9}$ & $1.38^{*} 10^{-3}$ \\
$\mathbf{3}$ & $2.52^{*} 10^{12}$ & $1.83^{*} 10^{8}$ & $0.72^{*} 10^{-4}$ \\
$\mathbf{4}$ & $1.62^{*} 10^{12}$ & $1.80^{*} 10^{8}$ & $1.11^{*} 10^{-4}$ \\
$\mathbf{5}$ & $2.908^{*} 10^{13}$ & $7.27^{*} 10^{8}$ & $2.5^{*} 10^{-5}$ \\
\hline
\end{tabular}




\section{Polyclonal Phage ELISA}

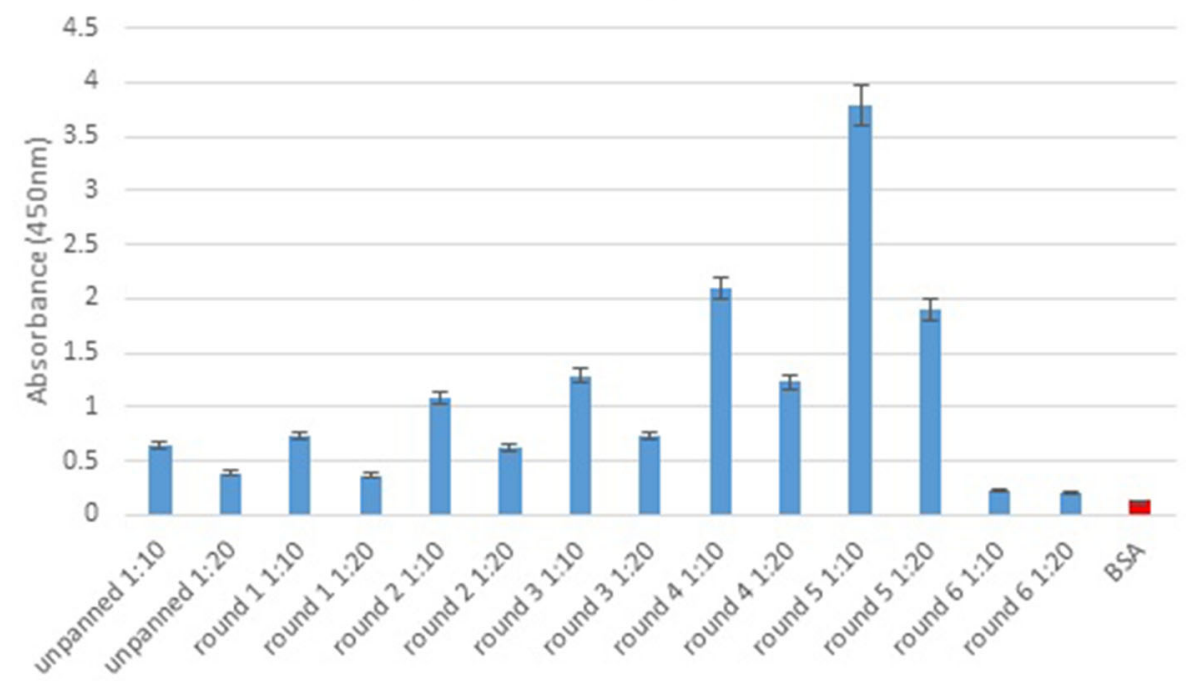

Fig. 1 Results of polyclonal phage ELISA related to six biopanning rounds against anti ExoA- DI protein. The plates were coated with $24 \mu \mathrm{g} / \mathrm{ml}$ domain I protein, blocked with 3\% BSA, and the binding of precipitated phages from different rounds was determined using anti-M13-HRP at 1:2000 dilution. Absorbance values are represented as the mean \pm standard deviation (SD) of three independent determinations. Error bars show the standard deviation for each set of data

phages were increased from $1.40^{*} 10^{6}$ in the second round to $7.27 * 10^{8}$ in the fifth round. However, the enrichment rate was again reduced in the 6th round. These findings were indicating an effective screening to obtain specific phages against ExoA-DI. A polyclonal phage ELISA was performed after each biopanning round to examine the specificity of the eluted phages against ExoA-DI.

The BSA was used as the negative control and displayed a weak signal in ELISA (Fig. 1). Based on the results, the lowest OD was related to the wild-type phages before panning. After six rounds of biopanning, the 5th round

\section{Monoclonal Phage ELISA}

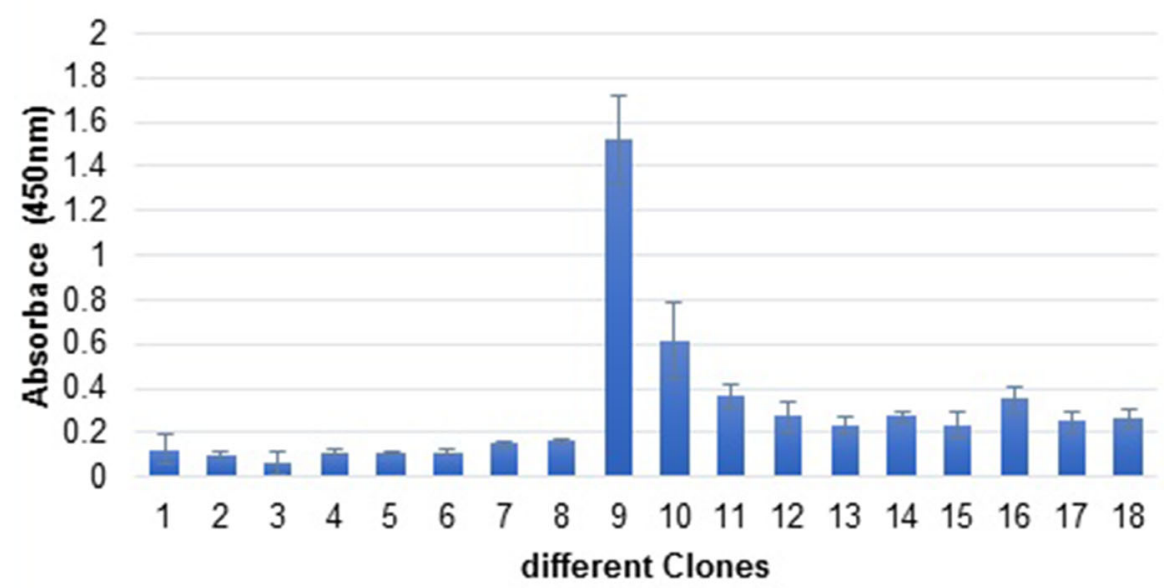

Fig. 2 The specificity of the selected phage clones for ExOA-DI. To perform a monoclonal phage ELISA, $60 \mu \mathrm{m} / \mathrm{ml}$ of ExoA-DI was coated per well of ELISA plates, and $100 \mu \mathrm{l}$ supernatant of each phage clone was separately added per well. Clone number 1 related to the wild-type phage that was used as the negative control. The reactivity was assessed using anti-M13-HRP at 1:2000 dilutions. Absorbance values were recorded as the mean \pm SD for three independent determinations. Error bars are indicating the standard deviation for each set of data 


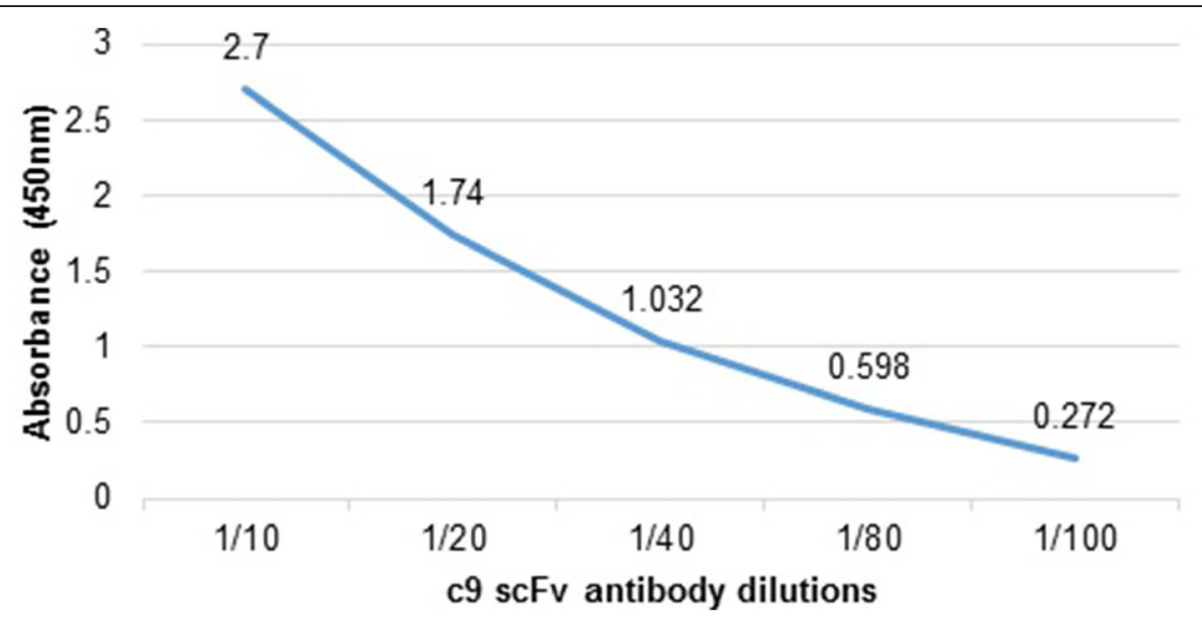

Fig. 3 Comparison of the reactivity of different dilution of $\mathrm{C} 9 \mathrm{scFv}$ phage clone with ExoA-DI

indicated the highest binding reactivity to ExoA-DI, so it was selected for further studies.

\section{Determination of the binding of scFv phage clones to ExoA-DI by monoclonal phage ELISA}

We examined more than 100 phage clones randomly from the fifth round, among which 18 specific phage clones were identified by monoclonal phage ELISA with optical densities 0.12 to 1.533 showing significant differences in the binding activity of selected phage clones. Among positive clones, one of the positive phage clones (C9) with higher reactivity to the domain I was used for further analysis (Fig. 2). The reactivity of serialy diluted C9 scFv against ExoA-DI revealed the high affinity of selected antibody clone (Fig. 3).

\section{Sequence analysis of the positive clones}

To confirm the presence of both VH and VL fragments in the positive clones, DNA was extracted from the 18 positive clones. PCR screening using PHEN and LMB3 specific primers results in amplifying a specific PCR fragment that appeared as a single $950 \mathrm{bp}$ band (Fig. 4).

In the next step, the integrity of the $\mathrm{C} 9 \mathrm{scFv}$ clone with the highest affinity was confirmed by sequencing. Blast analysis indicated that the nucleotide sequence is related to human $\mathrm{VH}$ and $\mathrm{VL}$ fragments. There was no amber stop codon and mutation in the selected clone. Analysis of CDR regions was performed by http://www.

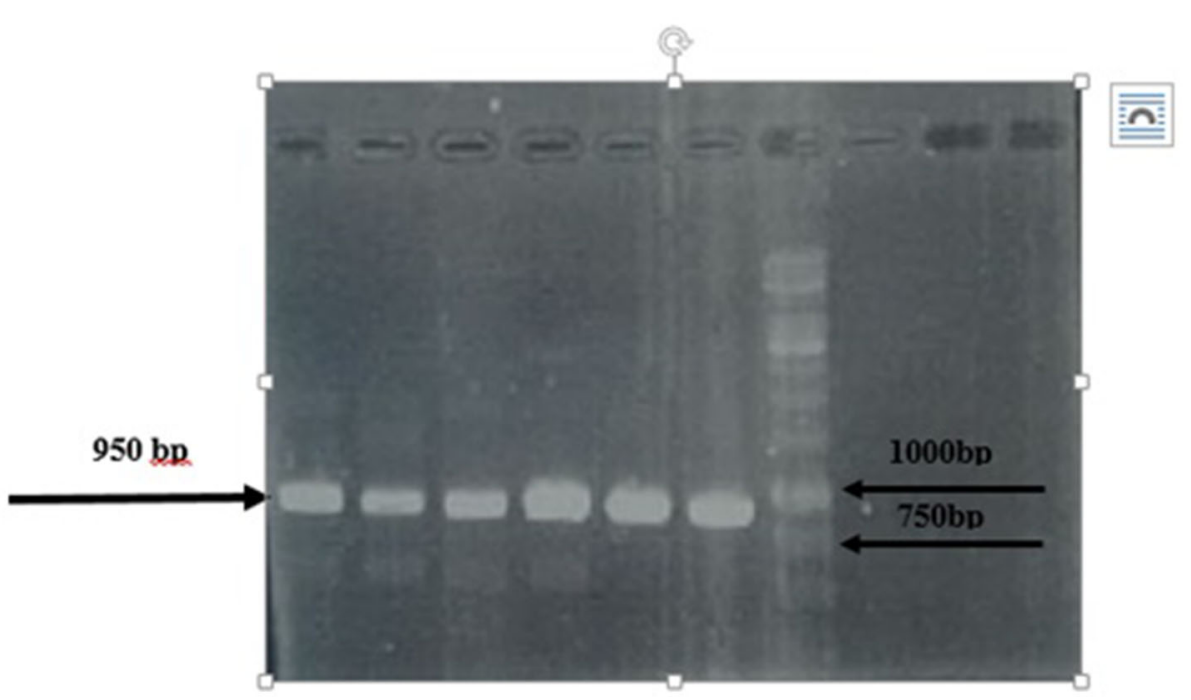

Fig. 4 PCR analysis of positive phage clones using vector-specific primers along with DNA size marker (1 kb size marker, Fermentas SM031) 


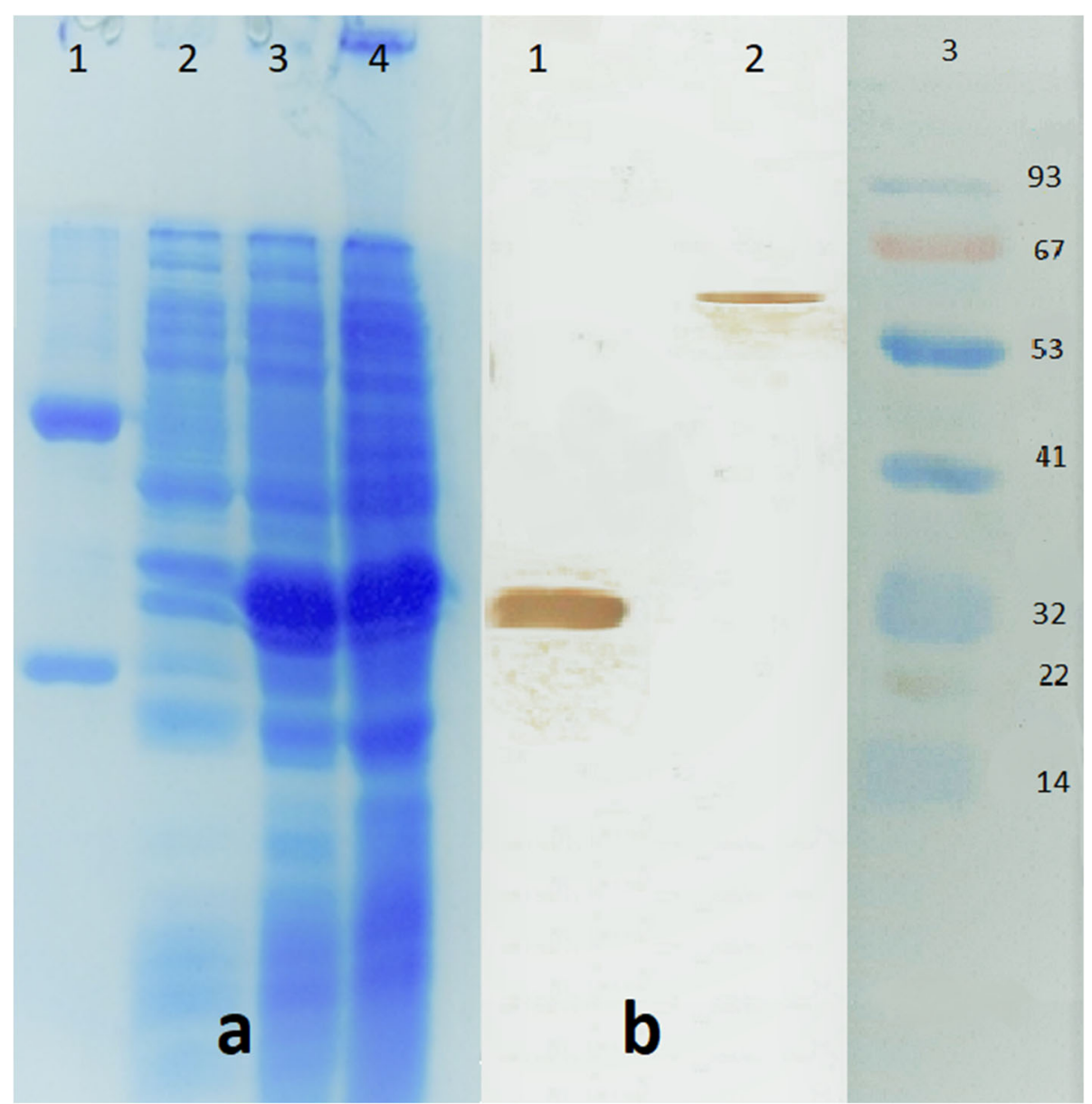

Fig. 5 a SDS-PAGE analysis of anti ExoA-DI expression in E. coli. The results revealed a high level expression of scFv. HB2151 containing scFv inserts were grown and induced with IPTG for scFv secretion. Lane1, lgG; Lane 2, c9 scFv clone before induction; lane 3, $16 \mathrm{~h}$ hour after induction, lane 4, $22 \mathrm{~h}$ after induction. $\mathbf{b}$ Western blot analysis of the selected scFv antibody against ExoA-DI and native exotoxin A. Exo-DI and native exotoxin A was electrophoresed through a 12\% SDS-polyacrylamide gel and transferred onto PVDF membrane along with a pre-stained protein size marker (abcam cat no. ab116027). The membrane was incubated with HRP conjugated protein $L$ and developed using DAB substrate. The size of scFv was observed in the expected size of about $30 \mathrm{KD}$ and $63 \mathrm{kDa}$. Lane 1, purified Exo A Dl; Lane 2, Native exotoxin A; Lane 3, prestained size marker

imgt.org/3Dstructure-DB/cgi/DomainGapAlign.cgi and displayed in Table 4.

\section{Assessment of the reactivity of selected scFv by western blotting}

After purification of the selected $\mathrm{scFv}$ (c9) by $\mathrm{Ni}$ NTA column, its purity was confirmed by SDS-PAGE, which showed a single band of $25 \mathrm{kDa}$. The reactivity of scFv to ExoA-DI was assessed by western blot. Results indicated a single band with a molecular weight (MW) of about $30 \mathrm{kDa}$ (Fig. 5), which was consistent with the calculated MW for the ExoA-DI protein [17].

Table 4 Sequence analysis of the C9 SCFv phage clone and its CDRs region

\begin{tabular}{lll}
\hline C9 sequence & MKYLLPTAAAGLLLLAQPAMAEVQLLESGGGLVQPGGSLRLSCAASGFTFSSYAMSWVRRAPGKGLEWVSTISSSGSATSYADSVKGRFTISR \\
& $\begin{array}{l}\text { DNSKNTLYLQMNSLRAEDTAVYYCAKTASSFDYWGQGTLVTVSSGGGGSGGGGSGGGGSTDIQITQSPSSLSASVGDRVTITCRASQSISSYLN } \\
\text { WYQQKPGKAPKLLIYNASYLQSGVPSRFSGSGSGTDFTLTISSLQPEDFATYYCQQSNAGPTTFGQGTKVEIKRAAAHHHHHHGAAEQKLISEE }\end{array}$ \\
\cline { 2 - 3 } & DLNGAA & VH \\
VL/VH & VL & QSISSY \\
\hline CDR1 & GFTFSSYA & NASYLQSGVS \\
CDR2 & ISSSGSAT & QQSNAGPTT \\
CDR3 & AKTASSFDY & \\
\hline
\end{tabular}




\section{Reactivity of recombinant scFV antibody with native exotoxin $A$}

Analysis of the reactivity of clone $9 \mathrm{scFv}$ antibody with purified native exotoxin A by ELISA showed that the scFv antibody could detect native exotoxin with high affinity (Fig. 6). This result indicates that the antibody produced against the domain I also had a significant reactivity with the native toxin.

\section{Discussion}

Exotoxin A is one of the most potent virulence factors in $P$. aeruginosa. With the increasing prevalence of multi drug resistant strains, it is necessary to develop alternative therapeutic approaches to combat resistant Pseudomonas infections. Neutralization of virulence factors such as exotoxin A is among promising strategies to control bacterial infections. Moreover, this strategy might affect drug resistance by maintaining the endogenous host-microbiome and creating less selective pressure on the endogenous bacteria [18]. Until now, various antibodies have been developed against different antigens of Pseudomonas, but none of them have been approved for clinical use [19].

Theoretically, antibody libraries contain various synthetic and semi-synthetic antibodies, facilitating the isolation of antibodies against any given antigens. At present, scFv phage libraries have an impactful payload in developing monoclonal antibodies without the need for experimental animals [20, 21].

Pseudomonas ExoA-DI has been shown to be responsible for the binding of toxin to animal cell receptors and plays a crucial role in the toxicity caused by
Pseudomonas exotoxin A. The aim of this study was to develop a fully human antibody against domain I of exotoxin A for potential use in neutralizing the toxic effects of Pseudomonas exotoxin.

In this study, a novel screening strategy was used for the elimination of nonspecific clones coupled with enrichment of specific clones during biopanning rounds. In this respect, monitoring output phage titers during screening rounds indicated a significant enrichment toward increasing specificity (64 fold) to EoA-DI. During six biopanning rounds, two specific clones with correct VH-VL regions were identified from the fifth round. One of the scFv clones (C9) with high affinity was selected for further studies. In order to generate antibody with high efficiency, the expression and purification of C9 scFv was again performed in E. coli. In a 2019 study by Sirijan Santajit et al., they produced human antibodies against subdomain Ia of exotoxin A of Pseudomonas using phage display technology [22]. However, in the present study, both subdomains Ia and Ib was used for isolation of human $\mathrm{scFv}$ antibody. Although the exact function of domain Ib has not been identified, it has been suggested that this part of exotoxin might be involved in cell recognition [23] or ADP ribosylation [24]. An older study also produced a mouse antibody against exotoxin $\mathrm{A}$, but due to the adverse immune responses related to mouse antibodies for humans, we decided to produce a completely human antibody [25]. S. Nathan [26] used phage display technology for isolation of the antibody against Burkholderia pseudomallei by multiple biopanning rounds. They observed high similarity (93\%) between different clones, and the main

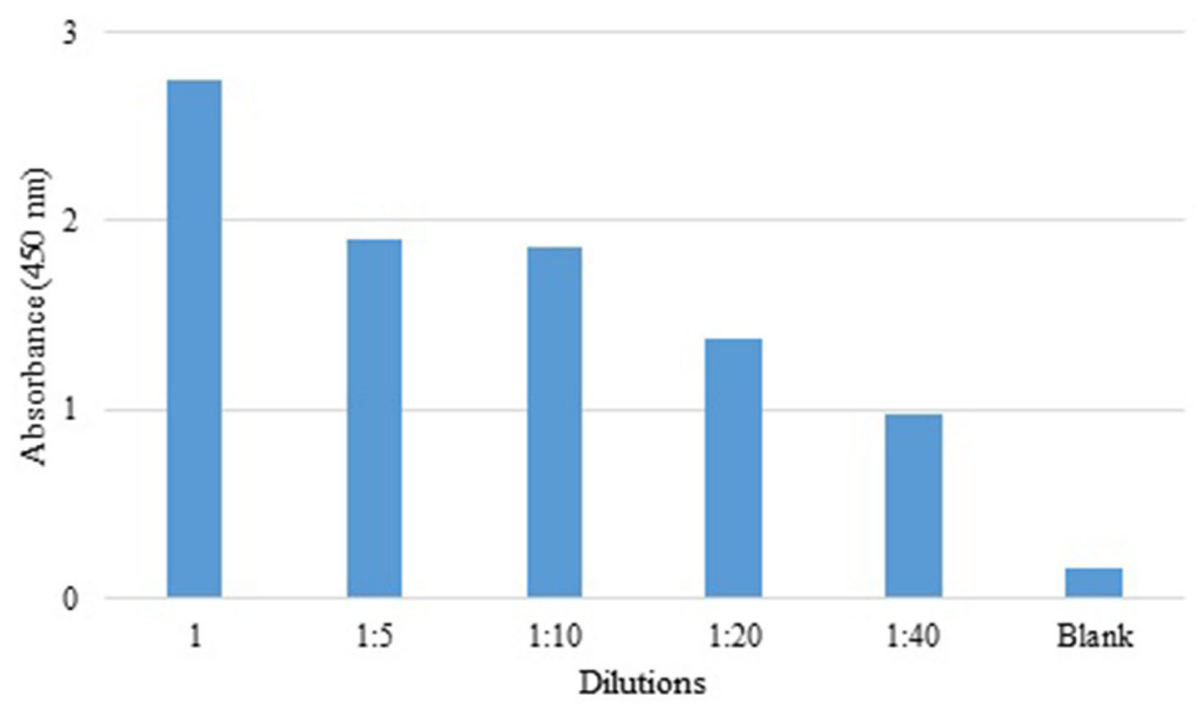

Fig. 6 The reactivity of different dilutions of C9 scFv antibody against native exotoxin A by ELISA method. The results indicated high reactivity of selected scFv antibody with native exotoxin A 
difference between the sequences of clones was related to the CDR3 area. In our study, the highest similarity was $93.9 \%$, and the different area in the sequences was related to CDRs [27].

The $\mathrm{scFv}$ clone 9 was purified with high solubility from periplasmic fraction. Based on ELISA results, the resultant anti-exotoxin $\mathrm{A} s \mathrm{scFv}$ specifically recognized both recombinant ExoA-DI and native exotoxin of $P$. aeruginosa with high affinity.

\section{Conclusion}

In this study, we generated and characterized a human anti-exotoxin A scFv with a significant binding potency to exotoxin A of $P$. aeruginosa. This scFv can potentially be considered for developing new therapeutic agents against $P$. aeruginosa infections.

\begin{abstract}
Abbreviations
scFv: Single-chain variable fragment; P: Pseudomonas; E. coli: Escherichia coli; Ni-NTA: Nickel-NTA; MRC: The Medical Research Council; IPTG: Isopropyl B-D1-thiogalactopyranoside; LB: Luria-Bertani; SDS-PAGE: Sodium dodecyl sulphate polyacrylamide gel electrophoresis; PBS: Phosphate-buffered saline: BSA: Bovine Serum Albumin; OD: Optical density; ELISA: Enzyme linked immunosorbent assay; PCR: Polymerase chain reaction; MW: Molecular Wight; kDa: Kilo Dalton; ExoA-DI: Exotoxin A domain I; Exo A: Exotoxin A; PVDF membrane: Polyvinylidene fluoride; anti-M13-HRP: Horseradish Peroxidase conjugated anti-M13; DAB: Diaminobenzidine
\end{abstract}

\section{Acknowledgments}

Not Applicable.

\section{Authors' contributions}

ZS conducted data collection and analysis; SF designed the study and supervised the project. MP and MT analyzed and interpreted the results; LR and ST wrote the manuscript draft. The authors read and approved the final manuscript.

\section{Funding}

This study was supported by National Institute for Medical Research Development (NIMAD) grant number 977043 . The funder had no role in the design of the study and collection, analysis, and interpretation of data and in writing the manuscript.

\section{Availability of data and materials}

The datasets used and/or analysed during the current study are available from the corresponding author on reasonable request.

\section{Declarations}

Ethics approval and consent to participate

This study was reviewed and approved by the ethical committee of the National Institute for Medical Research Development, Iran.

\section{Consent for publication}

Not applicable.

\section{Competing interests}

Authors declare that they have no competing interest.

\section{Author details}

'Drug Applied Research Center, Tabriz University of Medical Sciences, Tabriz, Iran. ${ }^{2}$ Department of Cellular and Molecular Biology, Faculty of Science Faculty, Azarbaijan Shahid Madani University, Tabriz, Iran. ${ }^{3}$ Biotechnology Research Center, Tabriz University of Medical Sciences, Tabriz, Iran.

${ }^{4}$ Nanotechnology Research Center, Tabriz University of Medical Sciences,
Tabriz, Iran. ${ }^{5}$ Infectious and Tropical Diseases Research Center, Tabriz University of Medical Sciences, Tabriz, Iran.

Received: 26 September 2020 Accepted: 8 March 2021

Published online: 24 March 2021

\section{References}

1. Ellis, Ronald W, editors. Vaccines: New approaches to immunological problems. Butterworth-Heinemann; 2014;20.

2. Elzaim HS, Chopra AK, Peterson JW, Goodheart R, Heggers JP. Generation of neutralizing antipeptide antibodies to the enzymatic domain of Pseudomonas aeruginosa exotoxin A. Infect Immun. 1998;66(5):2170-9. https://doi.org/10.1128/IAl.66.5.2170-2179.1998.

3. Allured VS, Collier RJ, Carroll SF, McKay DB. Structure of exotoxin A of Pseudomonas aeruginosa at 3.0-angstrom resolution. Proc Natl Acad Sci. 1986;83(5):1320-4. https://doi.org/10.1073/pnas.83.5.1320.

4. Wolf $P$, Elsässer-Beile U. Pseudomonas exotoxin A: from virulence factor to anti-cancer agent. Int J Med Microbiol. 2009;299(3):161-76. https://doi.org/1 0.1016/j.jijmm.2008.08.003.

5. Pollack M, Callahan L, Taylor NS. Neutralizing antibody to Pseudomonas aeruginosa exotoxin in human sera: evidence for in vivo toxin production during infection. Infect Immun. 1976;14(4):942-7. https://doi.org/10.1128/IA I.14.4.942-947.1976.

6. Kristensen $\mathrm{P}$, Winter $\mathrm{G}$. Proteolytic selection for protein folding using filamentous bacteriophages. Fold Des. 1998;3(5):321-8. https://doi.org/10.1 016/S1359-0278(98)00044-3.

7. de Wildt RM, Mundy CR, Gorick BD, Tomlinson IM. Antibody arrays for highthroughput screening of antibody-antigen interactions. Nat Biotechnol. 2000;18(9):989-94. https://doi.org/10.1038/79494.

8. Bals C, Schambach A, Meyer J, Scheper T, Rinas U. Expression and purification of bioactive soluble murine stem cell factor from recombinant Escherichia coli using thioredoxin as fusion partner. J Biotechnol. 2011; 152(1-2):1-8. https://doi.org/10.1016/j.jbiotec.2011.01.012.

9. Griffiths AD, Williams SC, Hartley O, Tomlinson I, Waterhouse P, Crosby WL, et al. Isolation of high affinity human antibodies directly from large synthetic repertoires. EMBO J. 1994;13(14):3245-60. https://doi.org/10.1002/ j.1460-2075.1994.tb06626.x.

10. Harrison JL, Williams SC, Winter G, Nissim A. Screening of phage antibody libraries. Methods Enzymol. 1996:267:83-109.

11. Eteshola E. Isolation of scFv fragments specific for monokine induced by interferon-gamma (MIG) using phage display. J Immunol Methods. 2010; 358(1-2):104-10. https://doi.org/10.1016/j.jim.2010.04.003.

12. Rahbarnia L, Farajnia S, Babaei H, Majidi J, Dariushnejad H, Hosseini MK. Isolation and characterization of a novel human scFv inhibiting EGFR v|l| expressing cancers. Immunol Lett. 2016;180:31-8. https://doi.org/10.1016/j. imlet.2016.10.008.

13. Wang $Y$, Zhang $X$, Zhang C, Liu Y, Liu X. Isolation of single chain variable fragment (scFv) specific for Cry1C toxin from human single fold scFv libraries. Toxicon. 2012;60(7):1290-7. https://doi.org/10.1016/j.toxicon.2012. 08.014.

14. West S, Sample AK, Runyen-Janecky LJ. The vfr gene product, required for Pseudomonas aeruginosa exotoxin A and protease production, belongs to the cyclic AMP receptor protein family. J Bacteriol. 1994;176(24):7532-42. https://doi.org/10.1128/JB.176.24.7532-7542.1994.

15. Deutscher MP. Guide to protein purification. 1st ed. Gulf Professional Publishing; 1990.

16. Liu PV, Yoshii S, Hsieh H. Exotoxins of Pseudomonas aeruginosa. II. Concentration, purification, and characterization of exotoxin A. J Infect Dis. 1973;128(4):514-9. https://doi.org/10.1093/infdis/128.4.514.

17. Ray K, Embleton M, Jailkhani B, Bhan M, Kumar R. Selection of single chain variable fragments (scFv) against the glycoprotein antigen of the rabies virus from a human synthetic scFv phage display library and their fusion with the fc region of human IgG1. Clin Exp Immunol. 2001;125(1):94-101. https://doi.org/10.1046/j.1365-2249.2001.01515.x.

18. Clatworthy AE, Lee JS-W, Leibman M, Kostun Z, Davidson AJ, Hung DT. Pseudomonas aeruginosa infection of zebrafish involves both host and pathogen determinants. Infect Immun. 2009;77(4):1293-303. https://doi. org/10.1128/IAl.01181-08

19. Horcajada JP, Montero M, Oliver A, Sorlí L, Luque S, Gómez-Zorrilla S, et al. Epidemiology and treatment of multidrug-resistant and extensively drug- 
resistant Pseudomonas aeruginosa infections. Clin Microbiol Rev. 2019;32(4): e00031-19.

20. Ma H, O'kennedy R. Recombinant antibody fragment production. Methods. 2017;116:23-33. https://doi.org/10.1016/j.ymeth.2016.11.008.

21. Baghban R, Farajnia S, Rajabibazl M, Ghasemi Y, Mafi A, Hoseinpoor R, Rahbarnia L, Aria M. Yeast expression systems: overview and recent advances. Mol Biotechnol. 2019;61(5):365-84.

22. Santajit S, Seesuay W, Mahasongkram K, Sookrung N, Ampawong S, Reamtong $\mathrm{O}$, et al. Human single-chain antibodies that neutralize Pseudomonas aeruginosa-exotoxin A-mediated cellular apoptosis. Sci Rep. 2019:9(1):1-15.

23. Voulhoux R, Taupiac MP, Czjzek M, Beaumelle B, Filloux A. Influence of deletions within domain II of exotoxin $\mathrm{A}$ on its extracellular secretion from Pseudomonas aeruginosa. J Bacteriol. 2000;182(14):4051-8. https://doi.org/1 0.1128/JB.182.14.4051-4058.2000.

24. Hwang J, Fitzgerald DJ, Adhya S, Pastan I. Functional domains of Pseudomonas exotoxin identified by deletion analysis of the gene expressed in E. coli. Cell. 1987;48(1):129-36. https://doi.org/10.1016/00928674(87)90363-1.

25. Shang H-F, Yeh M-L, Lin C-P, Hwang J. Characterization of monoclonal antibody B7, which neutralizes the cytotoxicity of Pseudomonas aeruginosa exotoxin A. Clin Diagn Lab Immunol. 1996;3(6):727-32. https://doi.org/1 0.1128/CDLI.3.6.727-732.1996

26. Shorr AF, Davies DB, Nathan SD. Outcomes for patients with sarcoidosis awaiting lung transplantation. Chest. 2002;122(1):233-8. https://doi.org/10.13 78/chest.122.1.233

27. Zanganeh S, Nejad HR, Mehrabadi JF, Hosseini R, Shahi B, Tavassoli Z, et al. Rapid and sensitive detection of staphylococcal enterotoxin $B$ by recombinant nanobody using phage display technology. Appl Biochem Biotechnol. 2019;187(2):493-505. https://doi.org/10.1007/s12010-018-2762-y.

\section{Publisher's Note}

Springer Nature remains neutral with regard to jurisdictional claims in published maps and institutional affiliations.

Ready to submit your research? Choose BMC and benefit from:

- fast, convenient online submission

- thorough peer review by experienced researchers in your field

- rapid publication on acceptance

- support for research data, including large and complex data types

- gold Open Access which fosters wider collaboration and increased citations

- maximum visibility for your research: over $100 \mathrm{M}$ website views per year

At $\mathrm{BMC}$, research is always in progress.

Learn more biomedcentral.com/submissions 